\title{
Attitudes towards English and ESP Learning for University Students: The Case of School of Economics and Law in Meknes
}

\author{
Nabila Elyazale \\ English at the School of law and Economics, University Moulay Ismail, Meknes, Morocco \\ Email: nabilaelyazale@gmail.com
}

How to cite this paper: Elyazale, N. (2019) Attitudes towards English and ESP Learning for University Students: The Case of School of Economics and Law in Meknes. Open Journal of Social Sciences, 7, 420-447. https://doi.org/10.4236/jss.2019.712033

Received: November 21, 2019

Accepted: December 28, 2019

Published: December 31, 2019

Copyright ( 2019 by author(s) and Scientific Research Publishing Inc. This work is licensed under the Creative Commons Attribution International License (CC BY 4.0).

http://creativecommons.org/licenses/by/4.0/

\begin{abstract}
This paper reports the results of a research conducted and English and ESP learning attitude in the Moroccan context. The study specifically investigated the language attitude of first-year economy and economy and law master students at the school of Law and Economics in Meknes, (University Moulay Ismail). The results revealed that both undergraduate and graduate students hold a positive attitude towards English and ESP learning at the cognitive, affective and behavioral levels. They also reveal a high degree of motivation in this regard.
\end{abstract}

\section{Keywords}

Attitude, Motivation, Language Learning, ESP

\section{Introduction}

Language is an indispensable means of communication among humans, in addition to other functions it performs in different fields. The English language is among the well-recognized languages in the world, given the economic power of its speaking communities. In many parts of the world, it is either a second or a foreign language. With the growing interest in learning English for integrative, instrumental or other reasons, there has been a similar growing interest in learning vocabulary related to different fields of study, known as the ESP.

Among the key elements in language high achievement is the motivation to do so. Motivation is, however, strongly related to other elements in the learning context, among which, the attitude the learner holds towards this language. In the context of English as a second language or as a foreign language, research has proved the importance of attitude and motivation for the learning situation. In 
the Moroccan higher education context, the English language and ESP have been integrated in the universities with the new educational reforms. However, and the fact that English is a foreign language in Morocco, university students who are not language majors may hold a negative attitude towards this language.

The aim of the present research is to investigate university students' attitude towards English and ESP learning in the Moroccan context, and specifically of undergraduate economy and Master economy and law students. Investigating English and ESP learning attitudes will be a first step towards making the needed alterations in the educational setting for a better learning context. This paper is organized in eight sections, the first five sections of which provide the theoretical background for the present study, while the last three sections are devoted to the details of the empirical study. The theoretical background involves definitions attributed to attitude from different fields of research, describing its characteristics as a human construct. Then, there is a description on how attitude is approached in the language research, and in relation to the concept of motivation. There is also a brief description of prior research conducted in the context of language attitude and motivation, and the last section as a theoretical background focuses on ESP and ESP research. The three other sections describe the educational framework of English Language Teaching in Morocco to set the background for the research methodology of the present study. The last section is devoted to results' presentation and discussion. The first section will briefly portray attitude' suggested definitions and some of its characteristics.

\section{Attitude Definition and Characteristics}

Attitude is a Man-associated construct used to "explain the direction and persistence of human behavior" Baker (1992: 10) [1]. Baker (1992: 12) [1] mentions that the term has Latin and Italian origin and it refers to "having a tendency towards certain action". Chaiklin (2011: 33) [2], adds that empirical research on attitude did not begin in the social sciences until the 1920s.

A bundle of definitions was proposed trying to identify its scope. Among the proposed definitions of attitude as a scientific element and in the field of social psychology where the term was first coined, Banaji and Heiphetz (2010: 348) [3] state, "we are creatures of preferences, Bundles of preferences characterizing every living organism". And that "the group that gave this concept scientific birth in the early $20^{\text {th }}$ century chose attitude as a name to refer to such preferences." Baker (1992: 11) [1] considers attitude as a "fundamental concept of social psychology varying from religion, sports, race, language", adding that language is "an important explanatory variable" to attitude. Eagly and Chaiken (1993: 1 in Banaji and Heiphetz 2010: 351) [3] attribute "evaluation" to attitude stating that it is a "tendency that is expressed by evaluating a particular entity with some degree of favor or disfavor". Petty, Wegener and Fabrigar 1997: 611 in Banaji and Heiphetz 2010: 352 [3], emphasize that the concept of evaluation is central to the definition of attitude, noting that "attitudes have been defined in a 
variety of ways, but at the core is the notion of evaluation". Social-psychology, thus, associate attitude to preferences humans attribute to different elements in their environment. These preferences may lead to evaluating, and or taking action towards the target element; and that the study of the attitude towards these elements may shed more light on this complex-human characteristic.

Attitude was also defined as a cognitive concept. Lanos (2014: 104) [4] reported on prior research on the nature of the hypothetical nature of attitudes. She states that attitudes having a cognitive construct are in the form of knowledge. Smith (1996: 894) [5] specifies this knowledge as schemas, beliefs and stereotypes. These schemas as Lanos (2014: 104) [4] emphasizes can be activated in the needed context. Being a form of knowledge, this cognitive attribute to attitudes seems to provide the concept with real existence in the human brain. The sociological perspective of attitude, on the other hand, emphasizes "verbal expression" as an intention to act. Chaiklin (2011:32) [2] explains "verbal expression", as an overt action to preferences and evaluations. This sociological perspective seems to take action into account since a social context is present. Ross and Lepper (789 in Banaji and Heiphetz 2010: 348) [3] broadens the social perspective to include the socio-cultural context stating that, "it is a concept which escapes the ancient controversy concerning the relative influence of heredity and environment ... the term is likewise elastic enough to apply either to the dispositions of single individuals or broad patterns of culture".

These definitions consider attitudes from different angles through which different attributes to the term emerge: preferences, knowledge, action, culture etc. Likert (1953: 9) [6] specifies that attitude definitions, generally speaking evolve around, "two chief conceptions: first, that attitudes are dispositions toward overt action; second, that they are verbal substitutes for overt action". In other words, attitudes lead to action or are at least verbally translated. Being related to action or to other elements, attitudes do not seem to be a simple construct. Researchers reveal that this concept is complex and it displays some characteristics.

One common attribute to attitudes is implicitness or explicitness; that is the possibility to observe them directly or indirectly. Baker (1992: 11) [1] considers that, "Attitudes are latent, inferred from the direction and persistence of external behavior". However, Gawronski (2007: 574) [7] states that attitudes can be both explicit and implicit and that "... implicit attitudes differ from explicit attitudes in that the former reflect unconscious (rather than conscious) attitudes". In other words, a researcher needs to know what type of attitude is needed to be identified to select the reliable instrument to trigger it. Banaji and Heiphetz (2010: 377) [3] support this view claiming that, “... attitudes are not always consciously accessible or controllable, but nevertheless guide behavior"

Another characteristic of attitudes is related to its stability as a concept. In fact stability and instability of attitudes seems to be approved in research. Schwarz (2007: 639 in Banaji and Heiphetz 2010: 352) [3], considers that, "attitudes do not necessarily exist in some performed state but can be built, created, generated, on the spot, in fine-tuned responses to contextual demands" In other words, 
an attitude may be formed instantly if the context requires it. Gawronski (2007: 574) [7] also supports this idea, generalizing the instability of attitudes to most contextual circumstances. Likert (1953: 8) [6] also considers attitudes as flexible elements since they relate to personality; and personality may change depending on personal and or environmental factors.

Some of the opposing views on the instability of attitudes come also from $\mathrm{Ba}$ naji and Heiphetz (2010: 352) [3], who approve the stability of the concept arguing that attitudes are related to people's experiences some of which are replicated. Banaji and Heiphetz (2010: 352) [3] state, "Given that human beings do learn, and learning means remembering in some form, why should attitudes not reveal some stability? They are, after all, products of repeated experiences that reinforce particular object-attribute pairings and provide similar responses to the same stimulus over repetitions". Baker (1992: 11) [1] also supports this idea stating, "Attitudes are a convenient and efficient way of explaining consistent patterns in behavior". However, according to Lanos (2014: 100) [4], most researchers agree that attitudes are not stable but they change.

Baker (1992: 12) [1] suggests another characteristic of attitude. He considers that attitudes can be both an "input" and an "output". It means that an attitude as an input can be a key or the source element in triggering positive or negative action towards an object. He provided the example of a favorable attitude to language or mathematics which can lead to good achievements in these target objects. Attitudes can be an output: a result or an income of an experience for instance. Baker provided the following example: learners may develop a positive attitude towards "reading" after attending a reading program.

Lanos (2014: 98-99) [4] summarized the most common characteristics describing attitudes and which most prior research agreed on. First, attitudes are hypothetical in the sense that they cannot be observed directly, although this characteristic may oppose the cognitive aspect of attitudes as a form of knowledge. Second, attitudes have an evaluative nature; objects for instance are given positive or negative attributes and this usually forms an evaluation of that object. Third, and in relation to the evaluation, attitudes are about an object that can be: a person, an idea, etc. Fourth, attitudes are learned rather than being innate because they are formed out of a living, social, psychological, cultural ... environment. Finally, attitudes may guide action, in the sense that a particular attitude towards an object may trigger a particular action or response towards this object. One of the important target objects of attitude that have received ample consideration in research is language and language learning. The next section will expand on this point.

\section{Attitude and Language}

Generally speaking, and as attitude was defined in the first section, there seems to be a need for an object to base one's attitude. According to some prior research (in Lanos 2014: 124-128) [4], language can be considered as an object of 
attitude. However, this definition may not be taken for granted because of taking language as a simple concept, Lanos (2014: 124-128) [4]. Mckenzie (2010: 26) [8] specifies that language attitude is an "umbrella term" that covers new languages, languages spoken by minority, language groups, language lessons, and language preferences. Thus, the identification of language attitude needs to be considered from different angles. Baker (1992: 10) [1] emphasizes the importance of attitude in the language context stating, "the status, value and importance of a language is most often and mostly easily ... measured by attitudes to that language".

Lanos (2014: 124-128) [4] summarized the different definitions given to language attitude to come up with all the elements included in one's attitude towards language. Some suggested definitions involve the social dimension of language which refers to the language and its use in society; including the contexts where it is used and its speakers. Moreno (1998 in Lanos 2014) [4] and Baker (1992: in Lanos 2014: 128) [4] provided a more specific scope. So in addition to the attitudes towards the language itself and its social dimension, there is also attitude towards the learning situation and language planning etc. Lanos (2014: 129) [4] affirms that these elements related to language attitude may not necessarily correlate and that for example, a person may have positive attitude towards a language and not necessarily positive attitudes towards its native speakers.

Some of the aspects of language were revealed to affect the attitude toward the language as an attitude object. For instance, Mckenzie (2010: 25) [8] states that, "attitudes towards global languages such as English are likely to be strong". Globalization of a language is usually due to economic growth and power of its speaking nations, and this may lead to triggering the desire to learn this language for example, especially that a global language is a language that is recognized worldwide compared to languages used in more limited contexts. Another aspect of language attitude has to do with its stability and instability. In this regard, Lanos (2014: 130) [4] claims that language attitudes may "have a certain degree of stability, which allows for their identification, but can also change". The consideration of attitudes towards language may need to be flexible enough to notice the potential change of these attitudes. Lanos (2014: 131) [4] specifies that the possible reasons of language attitude change can have two sources: The first relates to "individual needs and motives", while the second is connected to the "social situation". The social situation involves ideologies, values, government policies, the social group using the language, etc. The individual situation may require the need to learn a language for career development and this may generate the issue of motivation that has been strongly associated with language and language attitude in research. The next section will delineate this point.

\section{Motivation and Language Attitude}

Motivation, generally speaking refers to the willingness and desire to do or achieve something. Oroujlou and Vahendi (2011: 995) [9] specify that "the core 
of motivation is what might be called passion, which related to a person's intrinsic goals and desires". Motivation can be considered then a trigger to goal achievement. Motivation has been integrated in language learning research for being an ample source in students' high learning growing desire for hard work and achievement. Baker (1992: 22) [1] mentions that this tradition started by Gardner and Lambert 1972 focusing on the role of attitudes and motivation in second language learning.

Gardner (1975: 3) [10] distinguished between language learning motivation and classroom learning motivation. The first one refers to the motivation to learn a second language, while the second one "focuses on the individual's perception of the task at hand, a perception influenced by a lot of factors: teacher, classroom atmosphere, course content, materials and facilities, and personal characteristics of the student. Thus, it seems that language learning motivation relates to the individual per say, meaning that this motivation comes from the learner's belief or conception about language learning, while the classroom learning motivation is affected positively or negatively by the educational environment where it takes place.

In the classroom context, Gardner 1972 (in Guerrero 2015: 97) [11] differentiates between instrumental and integrative motivations, specifically in second language learning. Integrative motivation refers to the desire of the learner to integrate the culture of the language group, while the instrumental motivated learner is a person whose target from language learning is instrumental in the first place, like for career development. Later on, Gardner (1985 in Lanos 2014: 163) [4] introduced "integrativeness" that refers to a high degree of interest in the language learning and it comprises attitudes towards the language group, interest in the language, and the orientation of integrating with the language group. It seems that Gardner's view on motivation is strongly related to the social context of its use, as integrativeness and integrative motivation suggest, especially that the notion on "interest in the language" was not clearly specified in terms of sources of interest in the language. This is why, the Gardner's model of motivation has been criticized for being contextualized in the social sphere rather than the language learning context; and it excludes the cognitive aspect to learn, (Dornyei 1994: 273) [12]. Dornyei (1994: 276/280) [12] tried to present a view on motivation from an educational angle and he argues that this educational aspect of motivation is not restricted to integrative and instrumental motivation. He describes three levels of motivation: the language level, the learner's level and the learning situation level. The language level involves the desire to get knowledge, to have foreign language friends in addition to travel orientations. The learner's level includes the degree of self-confidence, language use anxiety, and his/her own perception of language competence and self-efficacy. The learning situation level relates to the motivational components of the language course (degree of the learner's satisfaction about his/her expectations from the course, the teacher's personality characteristics and group specific motivational components; That is, the goal of the students involved in the learning together 
(competitiveness, play rather than study, etc.), and the degree of their cohesion as a group to achieve the goal. Dornyei's motivational construct seems to be more efficient in deconstructing the language motivation as an individual choice and in the classroom context. It seems to be more detailed concerning the classroom motivation like including the learners' group as an influencing variable to motivate learners.

The importance of motivation in language learning seems to be undeniable. For example, Motivation has been categorized as a condition among others, to achieve grit in language learning, (Keegan 2017: 5) [13]. Grit as keegan (2017: 3) [13] considers, is the ability to work continuously and persistently while maintaining a high level of interest along the way to achieve one's objectives. Research has associated motivation to attitude in language and language learning contexts, and seems to have proved the existence of a strong link between the two. Lanos (2014: 11) [4] reported on different research about the connection between attitudes and motivation. Like motives can affect the attitudes (Eagly and Chaiken 2005) and attitudes can lead to the emergence of motivation (Feather's 1966). From another angle, Baker (1992: 20) [1] considers that motivation in addition to other elements may be used to measure attitudes. That is to say, the nature of attitudes a person holds towards an object will be measured by the degree of motivation he/she holds towards the object. When the attitudes are negative, the motivation degree will be minor compared to when the attitudes are positive. In the language context specifically, with the introduction of "integrativeness" as a motivational elements, Gardner (1975: 6) [10] connected it to language attitudes, stating, "integrativeness and attitudes toward the learning situation are expected to have an influence on the individual s level of motivation". Similarly to Baker, Gardner also believes that attitudes affect motivation. Gardner (1985: 10 in Karahan 2007: 75) [14] and Lanos 2014: 163) [4] even considers attitudes as components of motivation in language learning.

From a more global educational perspective taking the learning context into consideration, Clément and Gardner (2001 in Yo and Watkins (2011: 168) [15] categorize attitudes and motivation as influencing variables in the learning context in general. Also, the socio-educational model proposed by Gardner (1985 in Lanos 2014: 162) [4], that focuses on attitude and motivation towards second language learning, emphasizes the immense importance of attitudes and motivation in language learning. Oroujlou and Vahendi (2011: 998) [9] also support this point.

It seems that motivation and attitudes are inseparable in language learning. Attitudes affect the motivation of the learners and or can be a measurement for the degree of motivation. It can be stated that research conducted in the context of language motivation and attitude is abundant. Some empirical studies conducted on attitudes and motivation as separate influencing elements in the language context, while other studies tried to seek the potential connection between language attitude and motivation. In connection to language attitude, Lanos (2014: 133) [4] cited different research paradigms. The first focuses on language 
evaluation; the second on the speakers of the language and the third on language learning, choice, use etc. in the context of the latter, Soleimani and Hanafi (2013) [16] explored Iranian Medical students' attitude towards English language learning. They found out that they hold a highly positive attitude with males overriding females in attitude degree. Chakrani and Huang (2014) [17] investigated the relationship between attitude and language use among different social classes of Moroccan University students. The study reported the influence of the ideology of modernity on the attitudes of the students towards the selected language on interaction. Students from upper and middle classes consider French and English as the most suitable languages of classroom context to learn science and technical subjects. In addition, since this class of students holds positive attitudes towards these two languages, they feel more comfortable in using them for classroom instruction and even in other formal and informal contexts of language interaction.

Lanos (2014) [4] conducted a research study on multilingual Spanish second and fourth grade students' attitude towards English and English language learning. She specifically compared autochthonous students and immigrant students' attitude and found out that the formers hold less positive attitude towards English learning compared to immigrant students. Gokçe (2017) [18] investigated university students' attitude of all the four years of university studies towards the English course. He also gathered data on the students' prior experience with language learning discovering that such experience shape students' attitude towards present learning experience. Soomro et al. (2018) [19] investigated the attitude of Pakistani students' (involved in a certificate course of English), attitude towards learning English as a foreign language. The results revealed positive attitudes on the three attitude components: cognitive, emotional and behavioral. Mahmudi and Mahmudi (2018) [20] investigated medical students' and Human Sciences Students' attitudes towards English language learning in Iran. The research revealed that the field of study had significant impact on the cognitive and behavioral aspects of attitude but not the emotional. In addition, Gender had no significant impact on attitude. Asghar, et al. (2018) [21] explored the attitude of Art and Design students' attitude towards ESL in India discovering that students hold negative attitudes and that gender did not affect attitude significantly. It can be concluded that research on language attitude reveals positive view on second or foreign language learning generally speaking. This is maybe the case because of the worldwide spread of the English language in many parts of the world and may also be because the educational setting in most of these learning contexts is favorable and it encourages such learning.

Motivation in language learning seems to be well-recognized in research as well. Clément and Gardner (1977) [22] conducted a study on grade 10 and 11 Montreal Franco-phone students learning English as a second language to explore their motivational elements. The results showed that the individual motivation to learn English depends on the integrative motive, while the continua- 
tion of studying the language depends also on his/her actual competence level, self-confidence derived from his/her prior experience with the language. Furthermore, the motivational aspects are highly related to the students' attitude towards the language. Yo and Watkins (2011) [15] carried out a study on one University Western group and one Eastern group studying Chinese in China to investigate the contribution of motivation in self-reported Chinese language proficiency. It was found that the two elements have significant positive correlation but not as the main contributing element in self-reported language proficiency. Also, the western students made better than the Asian group in Chinese language proficiency thanks to their high levels of integrative motivation and lower levels of instrumental motivation and anxiety. Calvo (2015) [23] explored the possible influence of motivation on high school Spanish students' achievement based on L2 motivational self system and to find the relationship between the dimensions of L2 motivational self-system and language achievement. The results revealed strong relationship.

Given the importance of motivation and attitude in language learning, some research studies were conducted to investigate the two elements at the same time. According to Baker (1992: 22) [1] the tradition of connecting attitude to motivation in the language context started by Gardner and Lambert 1972 focusing on the role of attitudes and motivation in second language learning. Al-Tamimi and Shuib (2009) [24], investigated Yemeni Engineering undergraduate learners' motivation of English language learning. They specifically investigated three motivational constructs: the instrumental, the integrative and the personal motivation. The attitude concept included the students' attitudes regarding the use of English in the Yemeni social context, the educational context, the English language itself, and the culture of the English speaking world. The results revealed support for instrumental and personal reasons as sources of motivation to learn English. The learners also hold positive attitude towards the aforementioned elements of attitude.

Another study was conducted by Abdelkader and Amine (2018) [25] who investigated university (Saida University) students' attitude towards learning English as a foreign language in Algeria. The study results revealed that the students believe on integrative and instrumental motivations as the most influential elements for English learning and that the educational context (teachers, lessons, etc) affect their attitude towards the language learning process positively or negatively. Johnston et al. (2018) [26] explored the relationship between attitudes and motivation in multilingual context in Spain. They specifically investigated the impact of L1 (Spanish and Catalan) on university students' attitudes and motivation towards learning English. The results revealed that Spanish L1 students had slightly more positive attitude and motivation towards learning English than Catalan L1 students, but it was not a determining variable for both.

It is important to mention that the empirical work presented in this paper is not exhaustive but it gives a general idea about how motivation and attitude 
were investigated in the language context. It can be deciphered from prior research that Motivation and attitude can be considered essential in language learning in general as many research studies reveal. One subset of language learning that has also attracted research regarding attitude is the ESP. The ESP may be a more challenging subfield of language learning, and this may present an interesting angle to explore language attitude. The next section will shed light on the ESP element as has been embraced in language attitude research.

\section{English for Specific Purposes (ESP)}

ESP or English for Specific Purposes is "a subset of English as second or foreign language. It usually refers to teaching the English Language to university students or people already in employment, with reference to the particular vocabulary and skills they need", Wikipedia (2019) [27]. The ESP is a more technical context of language learning that has particular learning purposes rather than general aims as it is the case of language learning per se. It is also connected to adults learning contexts since it is related to the Job market needs. This is why, Williams (2014: 141) [28] specifies that ESP "has to do with specialized forms of discourse with which the majority of native speakers will be unfamiliar with". In other words, ESP is a challenging subfield of language learning even for native speakers, because it may exceed the mastery of the language to cover technicalities of different domains.

English for Specific Purposes has rapidly assumed a key position in language studies in general (Williams 2014: 137) [28], shortly after the Second World War, given the political and economic dominance of the U.S. English now is an international language that is considered "The fastest-spreading language in human history, English is spoken at a useful level by some 1.75 billion people worldwide-that's one in every four of us', Harvard Business Review (2017) [29]. The English Language, being associated with the world economic power, is "becoming even more the lingua franca of this globalized world", (Williams (2014: 137) [28]. Thus, ESP has gained an important position in education thanks primarily to the internationalization of English in the first place.

In relation to ESP research that exist nowadays, Williams (2014: 140) [28] mentions two strands: the pedagogical view with a learner's centered approach. The second strand searches a broader aspect of specialized discourse and culture, like investigating the subfields that set up ESP. ESP attitude research may be categorized within the pedagogical angle since it is based on the learner's view. The learner's attitude towards learning English seems to be as important as his/her attitude towards the ESP. Positive attitude would trigger motivation and high achievement in the language subfield. Even though this may not be taken for granted, research on ESP attitude seems to support this connection.

Ardeo (2003) [30] investigated the acquisition of specific vocabulary and attitudes towards English of Monolingual (Spanish) and Bilingual (Basque and Spanish) university students acquiring ESP within engineering, medical, nurs- 
ing, and Business Administration fields. The results revealed that bilinguals slightly outperformed the monolinguals in the ESP course but without significant difference. Also, both groups showed positive attitudes towards English but with no significant difference between them. Bruton (2009) [31] investigated tourism students' attitude towards General English and English for tourism in an eight-week course of English course in Thailand. He discovered that the students' attitude towards both general and tourism English was positive and did not differ significantly. In the Croatian context, Martinovic and Polijakovic (2010) [32] research aimed at understanding first year University students' attitudes towards learning English for specific purposes, and who are not language majors. The results demonstrated a positive attitude of these students towards English as a language, the process of English language learning and also a positive attitude towards the context of learning such as the teacher, the ESP content and the methodologies selected for English teaching. Loan (2017) [33] investigated second year university students towards ESP and its correlation with their English performance in Vietnam. The results revealed neither favorable nor unfavorable attitudes towards ESP. There was also a significant relationship between students' attitudes and their performance in English. In Algeria, Bouhafs and Boughari (2017) [34] explored the attitudes of first year Master Biology students at Tlemcen University towards their ESP courses. The results revealed that the students hold positive attitude and are highly motivated to learn English, being aware of its important to their scientific affiliation.

These empirical studies reveal that attitudes towards ESP may sometimes be strongly connected to the attitude of learning English, the educational setting and motivation, but not all the time as Loan's (2017) [33] research revealed. This may be due to different factors related to the learning context. Such attitude research may not be generalized to other educational contexts and each empirical study results may be attributed to the context of carrying out the research. Similarly to prior research on attitudes to language and ESP learning, the present paper aims at investigating the attitude of Economics and law university students at the School of Law and Economics in the Moroccan context. The second part of this paper will describe the details of the study, starting with a short portrayal of the English language in the Moroccan higher education system.

\section{The Context of the Study}

Like most of the rest of the world, the English language in Morocco is widely recognized "for its instrumental value as a means of communication with other nations and its importance for the Moroccan economy", Lazrak and Yechout (2017: 89) [35]. It also holds "a prestigious characteristic in the Moroccan culture which triggers an intrinsic motivation to learn the language" Lazrak and Yechout (2017: 89) [35]. It has a prestigious characteristic because it is a third language in the country, and not everybody is able to speak it or use it, unlike the French language. English, thus, seems to enjoy a high popularity through in- 
trinsic and extrinsic motivations to learn it, especially with the spread of technology where most of the web content, software programs are in English in the first place.

The growing awareness of the importance of the English language, especially for the economic growth has led the government to include it as part of the curriculum of higher education for non-English majors. Lazrak and Yechout (2017: 90) [35], in the context of ELT in the Moroccan higher education, claim that there has been a growing awareness of the importance of English to meet the job market requirements. There was, therefore, a change in content courses by "emphasizing modern language and specialization courses ... English for diplomacy, English for entrepreneurship and business, etc.". This English language Teaching strategy, encourages instrumental motivation as Hyde (2016: 297) [36] emphasizes.

The School of law and Economics (University Moulay Ismail) has incorporated the English language and ESP learning for its undergraduate and graduate majors, conforming to the higher education reform that took place about twelve years ago. The English language and Business English is taught to first year students, and all Master affiliations in economy and law have a two-hour weekly session of English and ESP learning as part of the curriculum. The present research involves both the undergraduate and the graduate students' population sample to investigate their attitudes towards English and ESP learning. As a first stage and given the fact that the students in the School of Economy and Law are not English majors, it seemed important to investigate their opinions concerning learning English and ESP. It is believed and based on prior research (sections four and seven) that attitude is strongly related to language learning, and holding a positive thinking about English may trigger grit, and high achievement in the language or ESP learning. The present research aims at investigating undergraduate and graduate students' attitude towards English and ESP learning. It also has the objective of determining factors related to the educational setting that influence the students' attitude towards learning English and ESP. This may help in reforming the educational setting in the best way possible to provide a better language learning setting. The research questions and hypotheses were formulated as follows:

1) What is the attitude that first year economics students at the School of Law and Economics hold towards the English language and ESP learning?

1.1) What are the educational setting elements which influence first year economics students' attitude towards English and ESP learning?

2) What is the attitude that Master Law and Economics Students at the School of Law and Economic hold towards the English language and ESP learning?

2.1) What are the educational setting elements which influence Master students' attitude towards English and ESP learning?

The research hypotheses were formulated as follows:

1) First year economics students at the School of Law and Economics hold a 
positive attitude towards the English Language and ESP learning.

1.1) Some educational setting elements influence First year economics students' attitude towards English and ESP learning.

2) Master Law and Economics students at the School of Law and Economics hold a positive attitude towards the English Language and ESP learning.

2.1) Some educational setting elements influence First year economics students' attitude towards English and ESP learning.

\section{The Research Methodology}

The sample selected for the present study consists of two university levels: the first includes two 244 first year students: 70 males and 174 females. They are economy majors and are taught English by three English professors. In each class, there are about 50 students. The second university level involves Master students from at least four out of nine Economics and law sub-affiliations to guarantee the presence of different economics and law Master specialization sub-fields. They consist of 210 students, $50 \%$ of which are males and the other $50 \%$ involve females. 79 of them are law affiliated while 131 belong to the Economy department. The selection of the sample was based on randomness following Dornyei's (2007: 97) [37] conception that, "Random samples are almost always more representative than non-random samples". It is believed that such samples would guarantee the presence of "characteristics similar to the population as a whole", Dorneyei (2007: 97) [37].

As for the sample size, the undergraduate whole population involves about 1000 students; with at least $50 \%$ of them or more not attending the English class, since attendance at the university is not compulsory. Thus, 244 of the population sample may be considered as a representative sample of the students who attend the English course. The Master group size involves five groups out of ten in economic studies: sustainable development of territories, marketing and commercial strategies, international economics management, logistics management, and evaluation of public policies. The law studies involve nine Master affiliations, four of which were selected for the present study and that include: political and religious studies, participatory banking operations and law, enterprises law, construction and real-estate. In each affiliation, there are about twenty students in each class. Thus, the size of the master students sample seems to include at least $50 \%$ of the whole master population.

The research instrument used for data collection is the questionnaire. The questionnaire is a well-recognized research instrument in attitude research. Baker states that (1992: 9) [1] "a survey of attitudes provides an indicator of current community thoughts and beliefs, preferences and desires". Banaji and Heiphetz (2010: 355) [3], add that "in many circumstances, the most appropriate measure of attitude or preference is obtained by asking participants for a verbal self-report'. Lanos (2014: 134) [4] supports this claims stating that the questionnaire is usually used in exploring attitudes towards language learning and 
the learning situation. Questionnaires have many advantages like "Describing the characteristics of the population by examining a sample of that group", and they are "capable of gathering a large amount of information", Dornyei (2007: 101) [37] and "when the researcher requires answers to a variety of questions", Mckenzie (2010: 42) [8]. In the present research, the questionnaire seems to be the most relevant instrument to gather data on attitude since the selected samples are large. The questionnaire usually guarantees gathering large and varied data in a short time. In addition, the aim of the present research is to get a general view on students' attitudes and not on particular students' attitude cases.

The present questionnaire involves eleven questions six of which are multiple-choice with a three scale options, while five questions are open-ended with four or five options as possible answers. The multiple choice questions were formulated three scales to meet the objective of the present research in terms of investigating the general tendency in attitudes. For instance, when the subjects are asked about the importance of English in terms of necessity, it does not matter if they consider it "necessary" or "very necessary" when they check the necessity choice. As for the other question types, the open-ended questions are easier to answer with the provision of different choices and leaving more freedom for the subjects to add their own possible suggestions as answers in the "other" option. The questionnaire tackles attitude from different angles. There are questions related to the subjects' opinion concerning the necessity of English and ESP in their study affiliations, as the cognitive of attitude suggests. There were also questions about the emotional side of English language and ESP learning, in addition to the behavioral side of attitude like frequency and reasons of skipping classes, in addition to the efforts made out of the classroom to learn the language or the ESP. There was also a question about their degree of motivation to attend the English course, and finally the open-ended questions investigated the elements which affect the subjects' attitude towards English and ESP learning.

The questionnaire was administered by the three professors to their first year economics students and Master students from the economics and law departments. The professors were instructed to explain the purpose of the questionnaire, the questions and vocabulary possible difficulties, and how to answer the different question types to their students. The subjects had the choice of completing the questionnaire in French or in English, in order to avoid possible question misunderstanding especially that the subjects' levels of English proficiency vary. The subjects were given ample time to answer the questions at their own pace and were ensured that there was no personal information to be involved in answering the questions. The gathered data was analyzed using the "Statistical Package for the Social Sciences" (SPSS) software as it is "the most commonly used in educational research" Dornyei (2007: 197) [37]. The multiple choice questions were assigned numerical values with one possible choice answer. The suggestions in the open-ended questions were also attributed numerical values with two options for each choice as yes and no options. This 
attribution helps in counting the frequencies and percentages of selecting or not selecting an answer. The "other" choice option answers were few, so they were only gathered in terms of possible answer categories manually. The data analysis revealed the following results as will be described in the last section of this paper.

\section{Results Description and Discussion}

This section will present results of the questionnaire data answer analysis and what they reveal concerning the subjects' attitude towards English and ESP learning. The results are based on counting frequencies and percentages. It is worth mentioning that the values reported concerning multiple-choice questions will be only the highest value percentages, as indicators of the general tendency on the subjects' attitude. The first sub-section will be devoted to results on the undergraduate students.

\subsection{First-Year Economy Subjects}

The results presented for this subjects category starts with a description of the population sample, and results on the cognitive side of attitude and potential factors affecting this concept. It ends with presenting the findings on the affective and behavioral side of attitude. Table 1 describes the population of the first-year economy subjects in terms of gender. Males constitute $28 \%$ while females constitute $71 \%$ of the population sample. The number of females exceeds that of males given the English class attendance reason. As aforementioned in section 10 on the population sample, it seems that females attend the class more than males. The aim of this paper, however, is to get the general tendency of language and ESP attitude regardless of gender differences.

The subjects believe in the necessity of the English language and the ESP learning with more than $50 \%$ of their total number, (Table 2). The findings on the cognitive side of language and ESP attitude of the sample subjects seem to vary in terms of reasons. For the General English element, the main three reasons for its necessity are communication purposes, exposure to the English culture and then, the knowledge and cultivation side. For the ESP element, the highest percentage goes for the availability of the reading materials related to courses with $60 \%$. This is not surprising since the subjects are economy students and English is the international language of business and economy. Relating to other reasons, the subjects believe in the instrumental motivation of the ESP in terms of work opportunity and promotion with more than $40 \%$, and consider English as the language of research. For the "other" reasons option, the subjects consider that English is powerful enough to provide them with opportunities to study abroad, immigrate and also get a job. For the ESP learning, subjects believe that it helps in enhancing their professional status, like an ESP knowledge will help improve the quality of task performance at work.

As for the elements that impact positively or negatively the subjects attitude towards English and ESP learning, Table 3 shows that the highest percentages 
Table 1. Description of the first-year economy subjects.

\begin{tabular}{ccc}
\hline & Frequencies & Percentages \\
\hline Males & 70 & $28 \%$ \\
Females & 174 & $71 \%$ \\
\hline
\end{tabular}

Table 2. Necessity of English and ESP for first-year economy subjects.

\begin{tabular}{cccccc}
\hline & \multicolumn{2}{c}{ General English } & & \multicolumn{2}{c}{ ESP } \\
\cline { 2 - 3 } \cline { 5 - 6 } & Frequencies & percentages & & Frequencies & Percentages \\
\hline Necessary & 213 & $87 \%$ & Necessary & 184 & $75 \%$ \\
Factors & & & Factors & & \\
Communication & 161 & $66 \%$ & Have a Job & 105 & $43 \%$ \\
Eng.Culture & 134 & $54 \%$ & Job.Promotion & 111 & $45 \%$ \\
Cultivation & 128 & $52 \%$ & Course Content & 50 & $20 \%$ \\
K.up to date & 110 & $45 \%$ & Reading material & 148 & $60 \%$ \\
A Must & 64 & $26 \%$ & Research & 101 & $41 \%$ \\
Other & 11 & $4 \%$ & Other & 4 & $1 \%$ \\
\hline
\end{tabular}

Table 3. Influence of educational factors on first-year economy subjects attitude.

\begin{tabular}{ccccc}
\hline & \multicolumn{2}{c}{ Positive Influence } & \multicolumn{2}{c}{ Negative Influence } \\
\cline { 2 - 5 } & Frequencies & Percentages & Frequencies & Percentages \\
\hline Teacher & 116 & $47 \%$ & 53 & $21 \%$ \\
Course Content & 77 & $31 \%$ & 71 & $29 \%$ \\
Methodology & 142 & $58 \%$ & 91 & $37 \%$ \\
C.Expectations & 96 & $39 \%$ & 102 & $41 \%$ \\
Other & 10 & $4 \%$ & 24 & $9 \%$ \\
\hline
\end{tabular}

belong to the teacher and methodology reasons with $47 \%$ and $58 \%$ respectively. It seems that the classroom activity and the teacher strongly shape the subjects' attitude regardless of the course content. Subjects also consider methodology as a negative influence on their attitude with $37 \%$ but the major reason is the course expectations with $41 \%$. Not meeting the expectations of the students in terms of quality or quantity seems also to strongly affect their attitude. Some of the suggested other negative reasons for impacting the subjects' attitude is their language level which is usually average or below and that hinders their motivation to make efforts. The other negative reason is the number of hours scheduled for English and ESP, which they consider not enough to make progress.

The affective and behavioral sides of attitude seem to be strongly present for the subjects. Table 4 reveals that More than $50 \%$ of them love the English language and make efforts out of the class to improve their English. Also, 55\% of the subjects rarely miss the English or ESP class even though class attendance is 
Table 4. Affective and behavioral components of attitude for first-year economy subjects.

\begin{tabular}{ccc}
\hline & Frequencies & Percentages \\
\hline Love English & Much: 175 & $71 \%$ \\
Motivation & Motivated: 184 & $75 \%$ \\
Efforts & Sometimes: 159 & $65 \%$ \\
Skip Class & Rarely: 136 & $55 \%$ \\
Skip: G.Reason & 200 & $82 \%$ \\
Skip: Motivation & 29 & $11 \%$ \\
Skip: Burden & 22 & $9 \%$ \\
Other & 7 & $2 \%$ \\
\hline
\end{tabular}

not compulsory, and $82 \%$ would miss the class for good reasons. In relation to motivation, more than 50\% feel motivated to attend English and ESP classes. This result goes hand in hand with effort outside the class and not missing their English and ESP classes. The other reason suggested for missing classes is not loving the language or ESP.

The findings on English and ESP learning attitude for the undergraduate subjects seem to be positive, as subjects believe in their necessity, are related emotionally to some extent to the English language, and take action like attending classes and making effort outside the class. They seem to be strongly motivated as well. The results on Master studies' subjects seem to be similar to the first-year economy students in terms of the three components of attitude. The next sub-section will describe the findings in details.

\subsection{Master Studies Subjects}

The results for Master subjects are presented in the same ordering as the first-year economy subjects. They start with a description of the subjects' population, the cognitive components of attitude and the elements affecting it, and the affective and behavioral sides of attitude. With this category of subjects, there was a cross tabulation on attitude in terms of gender and affiliation. Table 5 indicates an exact distribution of gender, with $50 \%$ for males and females. For affiliation, economy subjects seem to exceed the number of law subjects with $62 \%$ for economy and $37 \%$ for law subjects. Unlike the economy students, a significant number of law students are employees and their familiarity with the English language does not seem to be strong. This weak connection to English is also due to the fact that many of them studied Spanish in high school instead of English.

Table 6 presents students' cognitive conception on English and ESP attitude. A very big number of Master subjects believe in the necessity of English and ESP with $91 \%$ and $86 \%$ respectively. For the reasons related to the necessity of the English language, the highest percentages belong to the communication reason with $68 \%$ and keeping up to date with what is happening in the world with $53 \%$. Very close this percentage, Master subjects believe that English is the language of 
Table 5. Description of the master subjects.

\begin{tabular}{ccc}
\hline & Frequencies & Percentages \\
\hline Males & 105 & $50 \%$ \\
Females & 105 & $50 \%$ \\
Economy & 131 & $62 \%$ \\
Law & 79 & $37 \%$ \\
\hline
\end{tabular}

Table 6. Necessity of English and ESP for master studies subjects.

\begin{tabular}{cccccc}
\hline & \multicolumn{2}{c}{ General English } & & \multicolumn{2}{c}{ ESP } \\
\cline { 2 - 3 } \cline { 5 - 6 } & Frequencies & percentages & & Frequencies & Percentages \\
\hline Necessary & 192 & $91 \%$ & Necessary & 182 & $86 \%$ \\
Factors & & & Factors & \\
Communication & 144 & $68 \%$ & Have a Job & 103 & $49 \%$ \\
Eng. Culture & 101 & $48 \%$ & Job.Promotion & 56 & $26 \%$ \\
Cultivation & 110 & $52 \%$ & Course Content & 71 & $33 \%$ \\
K.up to date & 113 & $53 \%$ & Reading material & 148 & $70 \%$ \\
A Must & 60 & $28 \%$ & Research & 90 & $42 \%$ \\
Other & 31 & $14 \%$ & Other & 7 & $3 \%$ \\
\hline
\end{tabular}

knowledge and intellectualism with 52\%. For the "other" option, there was an emphasis on English as the language of research especially in economy. They also consider it as a powerful language spreading in the whole world. They also believe that learning English offers, training, job-opportunities, and to study abroad. As for the reasons of believing in the importance of ESP, subjects believe that this element helps first in the availability of reading materials connected to their affiliation with $70 \%$. They also believe that ESP helps in employment with $49 \%$ and $42 \%$ consider the ESP as the language of research. The few suggestions in the "other" reasons option was to be able to write in and to continue studying abroad in ones' field of specialty.

Table 7 presents results on the elements which affect the subjects' attitude. Like, undergraduates, a big number of Master subjects believe in the teacher personality and methodology as having positive effect on their attitude, followed by course content. Course expectations are believed to have a negative influence on the subjects attitude with $42 \%$ as well as the methodology with $33 \%$. Some other suggested negative effects relates to the number of hours devoted to the English and ESP course and which they consider not enough for progress. There was also the reason for the number of students in English and ESP class' size which is large enough not to allow every student to participate and improve his/her level. The other suggested problem was related to the subjects' proficiency in the language which is very or below average and which hinders their possible progress. 
Table 7. Influence of educational factors on master studies subjects attitude.

\begin{tabular}{ccccc}
\hline & \multicolumn{2}{c}{ Positive Influence } & \multicolumn{2}{c}{ Negative Influence } \\
\cline { 2 - 5 } & Frequencies & Percentages & Frequencies & Percentages \\
\hline Teacher & 137 & $65 \%$ & 54 & $25 \%$ \\
Course Content & 106 & $50 \%$ & 61 & $29 \%$ \\
Methodology & 161 & $76 \%$ & 70 & $33 \%$ \\
C. Expectations & 50 & $23 \%$ & 89 & $42 \%$ \\
Other & 3 & $1 \%$ & 26 & $12 \%$ \\
\hline
\end{tabular}

The Master subjects' answers on the affective and behavioral components of attitude seem to be similar to the undergraduate subjects. Table 8 reveals that $75 \%$ chose loving English "a lot" option, which means that many of them have a strong affective relation to the English language. $52 \%$ of the subjects make efforts "sometimes" and more than half of them rarely skip the English or ESP course. The main "other" suggested reason for skipping the class is commuting. Finally more than 50\% are highly motivated to study English and ESP.

The results on cross-tabulation related to gender (Table 9) reveal that there is no big difference between males and females belief on the importance of English and ESP. in addition, males reveal an affective connection to the English language (52\%) that is slightly different from that of females (47\%). Males and females are surprisingly equally motivated to learn English and ESP, and they reveal similar behavioral attitude component in terms of efforts devoted to improving the language, but not on the skipping rate, males skip the English and ESP course more often than females.

The cross tabulation on Master studies affiliations (Table 10) reveals higher percentages for economy subjects. More than $60 \%$ believe in the importance of English and ESP while only $33 \%$ of the law subjects believe so. Economy subjects seem also to be more strongly affective connected to English than law subjects. They show more motivation to attend the English course than law subjects, they make more efforts outside the class and they rarely skip their classes more than law subjects. Economy subjects seem to be more involved in the behavioral side of attitude than the law subjects.

\subsection{Results Discussion}

The results of the present research seem to indicate that undergraduate and graduate students at the School of Law and Economics hold a positive attitude towards English language and learning, and ESP learning, like many empirical studies reveal for English learning (Abdelkader and Amine 2018 [25], Soleimani and Hanafi 2013 [16], Lanos 2014 [4], Soomro et al. 2018 [19], Chakarani and Huang 2014 [17], Gokçe 2017 [18],) and for ESP learning (Bouhafs and Boughari 2017 [34], Bruton 2009 [31], Martinovic and Polijakovic 2010 [32], loan 2017 [33]). The students in the present research seem to be cognitively, affectively and 
Table 8. Affective and behavioral components of attitude for master studies subjects.

\begin{tabular}{ccc}
\hline & Frequencies & Percentages \\
\hline Love English & Much: 159 & $75 \%$ \\
Motivation & Motivated: 160 & $76 \%$ \\
Efforts & Sometimes: 111 & $52 \%$ \\
Skip Class & Rarely: 129 & $61 \%$ \\
Skip: G.Reason & 171 & $81 \%$ \\
Skip: Motivation & 33 & $15 \%$ \\
Skip: Burden & 16 & $7 \%$ \\
Other & 6 & $2 \%$ \\
\hline
\end{tabular}

Table 9. Cross Tabulation on gender differences in terms of cognitive, affective and behavioral components of attitude for master subjects.

\begin{tabular}{ccccccc}
\hline & E.Necessity & ESP. Necessity & Love English & Motivation & Efforts & Class Skipping \\
\hline Males & Necessary: $49 \%$ & Necessary: $48 \%$ & A lot: $52 \%$ & Motivated: $50 \%$ & Sometimes: $50 \%$ & Rarely: $41 \%$ \\
Females & Necessary: $50 \%$ & Necessary: $51 \%$ & A lot: $47 \%$ & $50 \%$ & $49 \%$ & $58 \%$ \\
\hline
\end{tabular}

Table 10. Cross tabulation on affiliation differences in terms of cognitive, affective and behavioral components of attitude for master subjects.

\begin{tabular}{ccccccc}
\hline & E.Necessity & ESP. Necessity & Love English & Motivation & Efforts & Class Skipping \\
\hline Economy & Necessary: $66 \%$ & Necessary: $65 \%$ & A lot: $62 \%$ & Motivated: $60 \%$ & Sometimes: $63 \%$ & Rarely: $76 \%$ \\
Law & Necessary: $33 \%$ & Necessary: $34 \%$ & A lot: $37 \%$ & $39 \%$ & $36 \%$ & $24 \%$ \\
\hline
\end{tabular}

behaviorally engaged in such learning process. More than $50 \%$ of the subjects in both groups believe in the necessity of the English language and the ESP learning, in spite of the differences in reasons of the necessity that exist between the two groups. For instance, Master groups opted more for keeping up to date and consider English as the language of knowledge and cultivation that the undergraduate groups. This may be due to age possible differences and which triggers different interest, opinion, and maturity degree. Undergraduate groups opted more for "culture" reason. However, for both groups "communication" reason remains the most selected option for both groups.

The subjects also believe that there are some elements in the educational setting that affect positively and negatively their attitude. A large number of both first year economy and Master students consider the teacher's personality and methodology as positively affecting elements in their perception of the English and the ESP learning. In addition, more than half of the subjects believe also in the methodology and course expectations as negatively affecting their perception of the language and ESP learning. A possible recommendation at this level is to improve the quality of teaching methodologies and the course content to meet the expectations of the students. Both groups reveal a high degree of motivation 
to attend English and ESP classes to learn quite similarly with $75 \%$ for the undergraduates and $76 \%$ for the Master students. This goes with some studies on motivation like Yo and Watkins (2011) [15] and Calvo (2015) [23]. More subjects in the Master groups seem to make more efforts outside the classroom with $76 \%$ than the undergraduate groups $65 \%$. This may be explained again by maturity factor since Master groups are older and many of them already hold a job and family responsibility. Further, graduate groups seem to attend English and ESP classes more with $61 \%$ rarely skipping compared to $55 \%$ for undergraduates. Attendance in Master classes is usually compulsory which is not the case for undergraduate students. However, both groups' highest percentage for reasons of skipping classes is having a good reason to do so, with $81 \%$ for Master groups and $82 \%$ for undergraduate groups.

The results on Master groups cross tabulation on gender reveal a small difference only in the frequency of skipping classes where males exceed females. This may due to commitment reasons. Attitude does not seem to differ concerning gender and this convenes with the Mahmudi and Mahmudi (2018) [20] study on gender effect on attitude. As for affiliation cross tabulation, the results reveal that economy students seem to be engaged with English and ESP more than the law students. This may be explained by the fact that law students generally speaking have an inferior proficiency of the English language than economy students. This may affect their degree of self-confidence and view on the necessity of English and ESP in their field of study. As aforementioned (Dornyei 1994 [12] section 4), many elements in the educational setting affect attitude and motivation to learn, like one's own perception of learning, and language anxiety which develops when the learner holds a less than average level in the language. This would automatically affect one's perception on the necessity of the language, considering that their field of study does not require English or ESP, as Gokçe (2017) [18]'s research revealed.

Ultimately, the findings of the present research seem to confirm the hypotheses investigated; that both undergraduate and Master studies students hold a positive attitude towards the English Language and the ESP learning. They also seem to be highly motivated in this regard. They report slightly different reasons for English and ESP necessity learning but they seem to recognize the importance of English and ESP regarding their learning affiliations in addition to other contexts. Both undergraduate and Master studies groups also believe that their attitude towards English and ESP learning can be influenced by the educational setting, regardless of the nature of the factor(s) selected or suggested as influencing element(s).

\section{Conclusion}

The present study investigated the English language and ESP learning attitude on the part of university students who are not English majors, in the Moroccan context. The findings reveal that both undergraduate economy and graduate 
economy and Master University students generally hold a positive attitude towards English and ESP learning on the three attitude components: the cognitive, the affective and the behavioral. The investigation of the educational setting elements that may affect students' language and ESP attitude has specified those elements which need improvement or change, namely, the teacher personality, class methodology, and course content expectations. Generalizing the results of this empirical research to other similar contexts should not be taken for granted for two reasons. The first is attributed to the characteristics of attitude concerning its stability. As researchers claimed (Section 2), language attitude may keep its stability for sometime but it may change with the changes in the learning context. The second reason relates to the educational setting itself which is usually peculiar to a specific educational institution. However, the results of the present research may be considered a first step towards investigating the university students' needs in economy and law fields in terms of curriculum development.

\section{Conflicts of Interest}

The author declares no conflicts of interest regarding the publication of this paper.

\section{References}

[1] Baker, C. (1992) Attitudes and Language, Multilingual Matters. Multilingual Matters Ltd., Philadelphia.

[2] Chaiklin, H. (2011) Attitudes, Behavior and Social Practice. The Journal of Social Welfare, 38, 31-54. https://scholarworks.wmich.edu/jssw/vol38/iss1/3

[3] Banaji, M.R. and Heiphetz, L. (2010) Attitudes. In: Fiske, S.T., Gilbert, D.T. and Lindzey, G., Eds., Handbook of Social Psychology, John Wiley \& Sons, New York, 348-388.

[4] Lanos, M.A. (2014) Language Attitudes in a Multilingual and Multicultural Context: The Case of Autochthonous and Immigrant Students in Catalonia. Doctoral Dissertation, University of Lleida, Lleida. http://www.researchgate.net/

[5] Smith, E.R. (1996) What Do Connectionism and Social Psychology Offer Each Other. Journal of Personality and Social Psychology, 70, 893-912. https://doi.org/10.1037/0022-3514.70.5.893

[6] Likert, R. (1932) A Technique for the Measurement of Attitudes. Archives of Psychology, 22, 5-55.

[7] Gawronski, B. (2007) Editorial: Attitudes Can Be Measured! But What Is an Attitude? Social Cognition, 25, 573-581. https://doi.org/10.1521/soco.2007.25.5.573

[8] Mackenzie, R.M. (2010) The Social Psychology of English as a Global Language, Attitudes, Awareness and Identity in the Japanese Context. Springer, Berlin.

[9] Oroujlou, N. and Vahendi, M. (2011) Motivation, Attitude and Language Learning. Procedia-Social and Behavioral Sciences, 29, 994-1000. https://doi.org/10.1016/j.sbspro.2011.11.333

[10] Gardner, R.C. and Smith, P.C. (1975) Motivation and Second Language Acquisition. Canadian Modern Language Review, 31, 218-233. 
https://doi.org/10.3138/cmlr.31.3.218

[11] Guerrero, M. (2015) Motivation in Second Language Learning: A Historical Overview and Its Relevance in a Public High School in Pasto, Colombia. HOW, 22, 95-106. https://doi.org/10.19183/how.22.1.135

[12] Dornyei, Z. (1994) Motivation and Motivating in the Foreign Language Classroom. The Modern Language Journal, 78, 273-284. https://doi.org/10.1111/j.1540-4781.1994.tb02042.x

[13] Keegan, K. (2017) Identifying and Building Grit in Language Learners. English Teaching Forum, 55, 2-9.

[14] Karahan, F. (2007) Language Attitudes of Turkish Students towards the English Language and Its Use in Turkish Context. Journal of Arts and Sciences Say, 7, 73-87.

[15] Yu, B. and Watkins, D. (2011) Attitudes and Motivation in Second-Language Acquisition: A Study on International Students in China from a Cultural Perspective. In: Chapman, D., Ed., Crossing Borders in East Asian Higher Education, Springer Science and Business Media, Hong Kong, 167-192. https://doi.org/10.1007/978-94-007-0446-6 8

[16] Soleimani, H. and Hanafi, S. (2013) Iranian Medical Students' Attitudes towards English Language Learning. International Research Journal of Applied Basic Sciences, 4, 3816-3823.

[17] Chakrani, B. and Huang, J.L. (2014) The Work of Ideology: Examining Class, language Use, and Attitudes among Moroccan University Students. International Journal of Bilingual Education and Bilingualism, 17, 1-14.

https://doi.org/10.1080/13670050.2012.718319

[18] Gokçe, D.D. (2017) Language Learning Attitudes: Ingrained or Shaped in Time? International Journal of Language Education, 1, 257-275. https://doi.org/10.18298/ijlet.2029

[19] Soomro, A.H., Bango, Z.A. and M.I.K. (2018) An Attitudinal Study of English as a Foreign Language in Sukkur Sindh Pakistan. Journal of Education and Educational Development, 5, 123-138. https://doi.org/10.22555/joeed.v5i1.1573

[20] Mahmoudi, M.K.M. and Mahmudi, S.K.M. (2018) Attitude of Iranian Students towards Learning the English Language. Journal of Clinical and Basic Research, 2, 35-39. https://doi.org/10.29252/jcbr.2.2.35

[21] Asghar, A., Jamil, I., Iqbal, A. and Yasmin, M. (2018) Learner Attitude towards ESL Learning: A Response from Art and Design. Open Journal of Social Sciences, 6, 81-88. http://www.scirp.org/journal/jss

[22] Clément, R., Gardner, R. and Smith, P.C. (1977) Motivational Variables in Second Language Acquisition: A Study of Francophones Learning English. Canadian Journal of Behavioural Science, 9, 123-133. https://doi.org/10.4236/jss.2018.65007

[23] Calvo, E.T. (2015) Language Learning Motivation: The L2 Motivational Self-System and Its Relationship with Learning Achievement. Universitat Autonoma de Barcelona. https://ddd.uab.cat/pub/tfg/2015/TFG elisabettort.pdf https://doi.org/10.1037/h0081614

[24] Al-Tamimi, A. and Shuib, M. (2009) Motivation and Attitudes towards Learning English: A Study of Petroleum Engineering Undergraduates at Hadhramout University of Science and Technology. Gema Online Journal of Language Studies, 9, 29-55. 
[25] Abdelkader, M. and Amine, M.D. (2018) Exploring Students' Attitude towards Learning English as a Foreign Language. Langues, Médiaset Sociétès, ALEPH. Vol. 6, N: 11.

[26] Johnston, S.M., Brage, L.B., Garau, M.J. and Noguera, J.S. (2018) Attitudes and Motivation in English Language Learning amongst Multilingual University Students in the Balearic Islands: The Effect of the L1 and Other Influential Variable. Journal of Multilingual and Multicultural Development, 40, 475-490.

https://doi.org/10.1080/01434632.2018.1531012

[27] https://www.wikipedia.org/

[28] Williams, C. (2014) The Future of ESP Studies Building on Success, Exploring New Paths, Avoiding Pitfalls. Open Edition Journals, 66, 137-150.

https://doi.org/10.4000/asp.4616

[29] Harvard Business Review Global Business Speaks English (2017). https://advancedlanguageinstitute.com/

[30] Ardeo, J.M.G. (2003) Attitudes towards English and ESP Acquisition as an L2 or L3 at University. Iberica, 6, 109-133.

[31] Bruton, M.W.C. (2009) An Evaluation of Students' Attitudes to the General English and Specific Components of Their Course: A Case Study of Hotel Employees in Chiang Mai, Thailand. ESP World, 8, 1-82.

[32] Martinovic, A. and Polijakovic, I. (2010) Attitudes towards ESP among University Students. Fluminensia, 22, 145-161.

[33] Loan, T.T. (2017) English Performance and Students' Attitude towards ESP: A Search for Congruence. Asian Journal of Educational Research, 5, 72-91.

[34] Bouhafs, S. and Boughari, A. (2017) Students' Attitude towards ESP Course: The Case of First Year Master Biology Students at Tlemcen University. Master Dissertation. http://dspace.univ-tlemcen.dz/

[35] Lazrak, M. and Yechout, Y. (2017) Issues in Moroccan Higher Education. International Journal of English Language and Translation Studies, 5, 86-93.

[36] Hyde, M. (2016) The Teaching of English in Morocco: The Place of Culture. ELT Journal, 48, 295-305. http://eltj.oxfordjournals.org/ https://doi.org/10.1093/elt/48.4.295

[37] Dornyei, Z. (2007) Research Methods in Applied Linguistics, Quantitative, Qualitative and Mixed Methodologies. Oxford University Press, New York. 


\section{Appendix:}

\section{Questionnaire:}

You are kindly invited to answer the following questionnaire. Its purpose is to get information on students' attitudes towards General, Business and Legal English learning. Thank you

Gender: $\square$ Male $\quad \square$ Female

Educational Level: $\square$ BE

$\square$ Master $\quad \square$ Law/ $\square$ Economy

1) How necessary do you see English Language Learning in Education in general?

$\square$ Necessary $\square$ A little necessary $\square$ Not necessary at all

2) What are the reasons that are important for you in English Language learning?

$\square$ communicate with foreigners

$\square$ know more about the English culture: readings/movies/music

口helps you be an intellectual person

$\square$ have an update: to know what is happening in the world

$\square$ you have to know it because you are an intellectual person

$\square$ Other

3) How necessary do you see Business/Legal English learning for your specialization?

$\square$ Necessary $\square$ A little necessary $\square$ Not necessary at all

4) What are the reasons that are important for you in learning Business and, or Legal English?

$\square$ helps you get a job

$\square$ helps you promote in your actual/future job

$\square$ helps you succeed in your major because some of the content of the courses is in English

$\square$ helps you in graduate education (Master and PhD) by having access to reading material

$\square$ helps you participate in conference activities as a researcher

$\square$ Other

5) What are the elements which affect positively your conception about general/business/legal English learning:

$\square$ the teacher

$\square$ the course content

$\square$ the methodologies used by the teacher 
$\square$ satisfaction with your expectations from the course

$\square$ other elements

6) What are the elements which affect negatively your conception about general/business/legal English learning:

$\square$ the teacher

$\square$ the course content

$\square$ the methodologies used by the teacher

$\square$ non-satisfaction with your expectations from the course

$\square$ other elements

7) How much do you like the English Language?

$\square$ much $\square$ a little $\square$ not at all

8) How motivated do you feel when you go to your general/business/legal English class?

$\square$ Motivated $\square$ a little motivated $\square$ not motivated at all

9) How often do you skip your general/business/legal English classes?

$\square$ Often $\square$ sometimes $\quad \square$ rarely

10) when you skip your English class, is it because:

$\square$ you have a good reason: you have to be at work, you are sick, or you have a problem, etc

$\square$ you do not feel motivated

$\square$ you feel it is a burden to your other subjects

$\square$ Other:

11) How often do you make efforts outside the class to improve your general/business/legal level in English?

$\square$ Often $\square$ sometimes $\square$ rarely

Vous êtes cordialement invités à répondre au questionnaire suivant. Son but est d'obtenir des informations sur l'attitude des étudiants à l'égard de l'apprentissage de l'anglais général, l'anglais des affaires et de l'anglais juridique. Je vous remercie

Sexe: $\square$ Homme $\quad \square$ Femme

Niveau d'éducation: $\square$ License

$\square$ Master: $\square$ Droit/ $\square$ Economie

1) Dans quelle mesure pensez-vous que l'apprentissage de l'anglais dans l'éducation en général? 
$\square$ Nécessaire $\quad \square$ Un peu nécessaire $\square$ Pas nécessaire du tout

2) Quelles sont les raisons qui sont importantes pour vous dans l'apprentissage de l'anglais?

$\square$ communiquer avec des étrangers

$\square$ en savoir plus sur la culture anglaise: lectures/films/musique

$\square$ vous aide à être une personne intellectuelle

$\square$ avoir une mise à jour: pour savoir ce qui se passe dans le monde

$\square$ vous devez le savoir parce que vous êtes une personne intellectuelle

$\square$ Autres raisons:

3) Dans quelle mesure pensez-vous que l'anglais des affaires/juridique doit être appris pour votre spécialisation?

$\square$ Nécessaire $\quad \square$ Un peu nécessaire $\quad \square$ Pas nécessaire du tout

4) Quelles sont les raisons importantes pour vous d'apprendre l'anglais des affaires et/ou juridique?

$\square$ vous aide à trouver un emploi

$\square$ vous aide à promouvoir votre travail (actuel/future)

$\square$ vous aide à réussir votre majeure car une partie du contenu des cours est en anglais

$\square$ vous aide dans vos études supérieures (maîtrise et doctorat) en ayant accès à du matériel de lecture

$\square$ vous aide à participer aux activités de la conférence en tant que chercheur

$\square$ Autres raisons:

5) Quels sont les éléments qui affectent positivement votre conception de l'apprentissage de l'anglais général/des affaires/juridique:

$\square$ l'enseignant

$\square$ le contenu du cours

$\square$ les méthodologies utilisées par l'enseignant

$\square$ satisfaction de vos attentes vis-à-vis du cours

$\square$ autres éléments:

6) Quels sont les éléments qui affectent négativement votre conception de l'apprentissage de l'anglais général/des affaires/juridique:

$\square$ l'enseignant

$\square$ le contenu du cours 
$\square$ les méthodologies utilisées par l'enseignant

$\square$ non-satisfaction de vos attentes par rapport au cours

$\square$ autres éléments:

7) Combien aimez-vous la langue anglaise?

口beaucoup $\square$ un peu $\square$ pas du tout

8) Quelle est votre motivation lorsque vous assistez à votre cours d'anglais général/des affaires/juridique?

$\square$ motivé $\square$ un peu motivé $\square$ pas motivé du tout

9) Combien de fois Ratez-vous votre cours d'anglais général/des affaires/juridique?

$\square$ souvent $\square$ parfois $\square$ rarement

10) Lorsque vous sautez votre cours d'anglais, est-ce parce que:

$\square$ vous avez une bonne raison: vous devez être au travail, vous êtes malade ou vous avez un problème, etc.

$\square$ vous ne vous sentez pas motivé

$\square$ vous pensez que c'est un fardeau pour vos autres matières

$\square$ Autre:

11) À quelle fréquence faites-vous des efforts en dehors de la classe pour améliorer votre niveau en anglais général/des affaires/juridique?

$\square$ souvent $\square$ parfois $\square$ rarement 